Table 1. VIABILITY of $V$. cholerae (N.C.T.C. 8021) ON 'LEMCO',

\begin{tabular}{|c|c|c|c|c|c|c|}
\hline & \multicolumn{6}{|c|}{ No. of colonies growing at dilutions } \\
\hline & $10^{-1}$ & $10^{-2}$ & $10^{-3}$ & $10^{-4}$ & $10^{-6}$ & $10^{-8}$ \\
\hline 'Lemco' agar & ce. & 11 & 0 & 0 & 0 & 0 \\
\hline Serum agar & cc. & unc. & 29 & 4 & 1 & 0 \\
\hline Blood agar & ec. & cc. & unc. & 27 & 6 & 0 \\
\hline
\end{tabular}

from the dried state, a factor which was not adequately supplied by serum.

It is possible that the population of $V$. cholerae culture is not homogeneous, and that there are cells able to grow on agar and others unable to do so without the addition of blood. To test this point, subcultures were made from the highest dilutions surviving on blood and on 'Lemco' agar and these were redried by the same method. So far there is no evidence to support the theory of a heterogeneous population, but long-term experiments are continuing. Constance SHaw

National Collection of Type Cultures,

Central Public Health Laboratory,

Colindale Avenue,

London, N.W.9.

Aug. 29.

${ }^{1}$ Fry, R. M., "Freezing and Drying", 107 (Institute of Biology) "Greaves, R. I. N., Nature, 153, 485 (1944).

Miles, A. A., and Misra, S. S., J. Hyg. (Camb.), 38, 732 (1938).

- Stamp, Lord, J. Gen. Microbiol., 1, 251 (1947).

${ }^{5}$ Proom, H., and Hemmons, L. M., J. Gen. Microbiol., 3, 7 (1949).

\section{Coenurus of Taenia brauni Setti parasitic in Man and Animals from the Belgian Congo and Ruanda-Urundi}

IN 1952 I was able to observe for the first time the life-cycle of Taenia brauni Setti (1897).

This tapeworm lives, in the adult stage, in the intestines of dogs and jackals in the Belgian Congo, and its larvæ, of the Coenurus type, have been found in Nature in wild rodents (Lemniscomys striatus L.).

On feeding laboratory-bred white mice with proglottids found in the droppings of parasitized dogs, I have succeeded in observing the development within them of Coenurus. On the other hand, I was successful in obtaining adult worms by feeding non-infected young dogs with fragments of Coenurus collected from wild rodents which. were naturally infected with the parasite ${ }^{1}$.

Afterwards I discovered the Coenurus of this tapeworm in numerous other wild rodents in RuandaUrundi (Rattus $r$. rattus L., Tachyoryctes ruandae Lönnb. and Gyld., Otomys irroratus vulcanius Lönnb. et Gyld., Grammomys surdaster Thom. et Wrought., and Dendromus pumilio lineatus Hell.) as well as in a monkey (Cercopithecus mitis doggetti Poc.) and in man (native). I never found it in sheep or goats nor in the wild rabbit, although this animal is very common in the region.

In wild rodents the Coenurus is most often found under the skin; but it may be found also on other parts of the body, namely, in the pleural and abdominal cavities and in the brain. The percentage of infected rats varies very much according to the places investigated, but in certain places it may reach up to 20 per cent of the animals examined.

Cerebral coenurosis of rodents has been found only on three Rattus $r$. rattus in the vicinity of Astrida. These Coenuri were rather big and situated in dif- ferent parts of the brain. Two of the three infected rats had also Coenuri on other parts of the body.

The case of cerebral coenurosis of the ape was discovered in the region of the Akanyaru (near Astrida). A globular Coenurus, $2 \mathrm{~cm}$. in diameter, was found embedded in the parietal lobe. This ape carried two other Coenuri : one, of the size of a large pea, was in part nestled in the apex of the heart; the other, much larger, was found in the region of the parotid gland.

In man (native) I have observed eight cases of coenurosis between the years 1948 and 1956, all situated under the skin. Of these eight cases, seven were children, the ages varying between 11 months and 5 years ; the last one was a boy of fourteen.

In four children the tumour was found along the ribs, in the four others it was found elsewhere on the trunk. The Coenurus was a solitary one in all patients. The dimension of the tumour varied from the size of an almond to that of a large plum; the form being globular or elongated.

The morphological study of all Coenuri showed that they belonged to Taenia brauni Setti. This tapeworm is extremely frequent in dogs and jackals throughout the Ruanda-Urundi area and Ituri region (Eastern Congo) and it is, together with Taenia hydatigena Pallas, the only cestode of the Taenia genus found in the dog of these regions ${ }^{2}$.

It is my opinion that the Coenurus found by Taramelli and Dubois under the skin of a native woman (of the Belgian Congo) belongs also to Taenia brauni ${ }^{3}$.

It is known that Coenuri of Taenia serialis or of Taenia multiceps, as parasites of man, occupy on this accidental host the same site as on the habitual intermediary host: respectively under the skin for Coenurus serialis and in the brain for Coenurus cerebralis.

The larva of Taenia brauni is less specific in the choice of its location in its natural hosts than those of the preceding species. It seems to me most probable that it would behave in the samo manner in man, and that, besides its normal location under the skin, one may expect to find it in the inner organs as well as in the brain. In this connexion it may be pointed out that, during recent years, four cases of human cerebral coenurosis have been described in South Africa all attributed by the authors to Taenia multiceps $^{4}$. It could be that these Coenuri belong, in fact, to Taenia brauni.

Provincial Medical Laboratory of Kivu,

$$
\text { A. FAIN }
$$
Bukavu, Belgian Congo.

Sept. 1.

Fain, A. Rev. Suisse Zool., 59, 487 (1952).

2 Fain, A. (two papers in the press).

${ }^{3}$ Taramelli, R., and Dubois, A., Ann. Soc. Belge Méd. Trop., 11, 151 (1931).

Becker, B. J. P., and Jacobson, S., Lancet, ii, 1202 (1951).

\section{Histological and Histochemical Observa- tions on the Intestinal Cells of Lambs and Kids absorbing Colostrum}

IT has been known for many years thai, intact colostral globulins are absorbed from the intestine of the young ruminant ${ }^{1}$ and recently it has been shown ${ }^{2}$, in the calf, that labelled globulins from colostral whey passed from the intestinal lumen into the intestinal lymphatics. Histological examination of 